\title{
Assessment of sexual risk behaviours of in-school youth: Effect of living arrangement of students; West Gojam zone, Amhara regional state, Ethiopia
}

\author{
Anemaw Asrat \\ College of Medicine and Health Sciences, Bahir Dar University, Ethiopia \\ Email address: \\ anemawasrat@gmail.com
}

To cite this article:

Anemaw Asrat. Assessment of Sexual Risk Behaviours of In-School Youth: Effect of Living Arrangement of Students; West Gojam Zone, Amhara Regional State, Ethiopia. American Journal of Health Research. Vol. 2, No. 2, 2014, pp. 78-83. doi: 10.11648/j.ajhr.20140202.18

\begin{abstract}
Background: Contemporary threats to adolescents' health are primarily the consequence of risk behaviors and their related adverse outcomes. Identifying factors associated with adolescents' risk behaviors is critical for developing effective prevention strategies. A number of risk factors have been identified, including familial environment; however, to the investigator's best knowledge, there have been only one previous study of possible differential vulnerabilities of in-school adolescents to risky sex in reference to parental influences and living arrangements in Ethiopia. Objective: To assess and compare sexual risk behaviours of preparatory students in West Gojam zone, in reference to their living arrangements Methodology: A comparative cross-sectional study was done in ten preparatory schools; West Gojam zone, Amhara National Regional State, Ethiopia. The study participants were selected based on probability proportional to size. A total of 314 students [104 living permanently in the corresponding towns and 210 not], were included in the study. Result: Seventy three (23.2\%) respondents had ever had sexual intercourse with an individual of the opposite sex. Disaggregated by sex, 55 (25.0\%) of males had had sex compared to $18(19.4 \%)$ of females. Twenty two students (33.3\%) reported having had two or more sexual partners in their lifetime (range 1-7, average 1.56). In the logistic regression analyses, controlling for observed covariates, age more than 20 years $[\mathrm{OR}=2.85 ; 95 \% \mathrm{CI}=1.07$ to 7.59$]$, having peer pressure to have sex $[\mathrm{OR}=4.43 ; 95 \% \mathrm{CI}=$ 2.02 to 9.69$]$ and perceived family connectedness $[\mathrm{OR}=0.96 ; 95 \% \mathrm{CI}=0.92$ to 0.99 ] continued to be significantly and independently associated with sexual activity Conclusion: A greater sense of connectedness to parents decreases the likelihood of sexual activity regardless of living arrangement, Parental monitoring, gender, khat and alcohol consumption, and parental education. Students with peer pressure to have sex are more likely to initiate sexual intercourse.
\end{abstract}

Keywords: Adolescent Health, Sexual Health, In School Youth

\section{Background and Statement of the Problem}

Adolescence is a phase of human development in which the impact of the biological processes of pubescence on behaviour is mediated by cognitive and emotional processes. These processes often reflect culturally specific beliefs, traditional practices, and contextual constraints arising from the socio-cultural and politico-economic macrosystem within which adolescent development is embedded.[1,2]

Despite their numbers, adolescents have not traditionally been considered a health priority since they have lower morbidity and mortality than older and younger age groups. Nonetheless, in some areas such as mental and sexual health, adolescents suffer disproportionately. [3]

There is evidence to show that adolescents left in the care of siblings without consistent adult supervision, have increased opportunities for sexual activity. The effectiveness of traditional family expectations and structures in shaping sexual beliefs, expectations and behaviors may be substantially weakened by population movement. [4]

Contemporary threats to adolescents' health are primarily the consequence of risk behaviors and their related adverse outcomes. Identifying factors associated with adolescents' risk behaviors is critical for developing effective prevention strategies. 
Following the opening of technical and preparatory schools for grade 11 and 12 senior high school students in selected urban sites in Ethiopia, it has become necessary for rural students to live in the nearby towns temporarily to attend school. Research conducted among young people in Ethiopia indicates that an increasing number are involved in unsafe sexual practices and hence face undesired health outcomes such as unplanned pregnancy, early childbirth, unsafe abortion and sexually transmitted diseases.

High-risk sexual behaviour puts people at risk for sexually transmitted infections (STIs), unplanned pregnancy, and being in a sexual relationship before being mature enough to know what makes a healthy relationship. Examples of high-risk sexual behaviour include: unprotected intercourse without male or female condom use, starting sexual activity at a young age, having multiple sex partners, having a high-risk partner (one who has multiple sex partners or other risk factors).

To the investigator's best knowledge, there have been only one previous study of possible differential vulnerabilities of in-school adolescents to risky sex in reference to parental influences and living arrangements in Ethiopia.[5]

\section{Objectives}

\subsection{General Objective}

To assess sexual risk behaviours of preparatory students in West Gojam zone, and compare them with reference to their living arrangements

\subsection{Specific Objectives}

1 To measure the prevalence of unsafe sexual practices

2 To compare sexual risk behaviours between students living with their parents and those living away from their parents

3 To assess the level of peer influence on sexual practice

4 To assess the level of communication on sexuality and HIV/AIDS between adolescents and their parents, peers, and families.

\section{Methodology}

A comparative cross-sectional study was done from December, 2011 to March, 2012 in preparatory schools in West Gojam zone, Amhara National Regional State, Ethiopia.

The study participants were selected based on probability proportional to size, size being the number of students in each preparatory schools. The sampling frames were obtained from the student registration books of the respective schools.

Sample size was calculated considering the "proportion of adolescents who are sexually experienced" as a key variable. Epi Info version 3.3, sample size and power calculation for cross-sectional studies was used to calculate the sample size needed.
A ratio of 2:1 was used to allow a further stratification of students living away from families as those who frequently visit their families (at least once in two months) and those who visit their families only for vacations (more than two months between visits on average).

Hence, Sample size: $n 1=99$ and $n 2=198$; Total sample size $=297$.

To allow for possible non-response during the actual survey, we increased the sample size by $10 \%$ to get a final sample size of 327. [109 for $\mathrm{n} 1$ and 218 for $\mathrm{n} 2$ ].

The data from participants were collected using a self-administered questionnaire. The questionnaire was originally developed in English and then translated into Amharic. It was then back translated to English by another person. Most of the items were adapted from existing surveys[5,6]. The Amharic language questionnaire was used to collect data after being pre-tested in schools outside the study area.

The quantitative data were checked for completeness and consistency. Data entry and analyses were performed using SPSS statistical packages (version 15 for Windows). First, descriptive analyses were carried out to explore the socio-demographic characteristics of the respondents. Bivariate analyses were carried out to examine the relationship between the outcome variables and selected determinant factors. Chi-square and t-tests was also used as appropriate. Factors for which significant bivariate association was observed were retained for subsequent multivariate analyses using multiple logistic regression. Odds ratios were used to assess the effect of living arrangement.

\section{Results}

\subsection{Socio-Demographic Characteristics}

The socio-demographic characteristics of respondents are shown in Table 1. Overall 314 students $(96.3 \%$ of estimated sample size) responded to the questionnaire completely. Of these, $104(33.1 \%)$ were permanent urban residents; 220 (70.3) males.

The mean age of respondents was $19.4( \pm 1.1)$ years. 246 (79.1\%) mothers and $185(61.5 \%)$ of fathers of respondents were illiterate. Parents of rural students were significantly more likely to be illiterate ( $p$-value $<0.0001$ ).

When we see the living arrangement of respondents in general, the majority $(31.2 \%)$ were living with friends followed by with relatives $(20.7 \%)$ and both biological parents $(20.4 \%)$.

For urban students, the most common living arrangements were living with both parents $(52.9 \%)$ or with one biological parent only $(27.9 \%)$, while a significant share of rural students lived with their friends $(45.7 \%)$ or relatives $(31.9 \%)$ [P-value $<0.0001]$

Three hundred three students $(96.5 \%)$ identified themselves as orthodox Christian, 9 (2.9\%) as Muslim and the rest other religion. 
Table 1. Percentage distribution of students by selected socio-demographic characteristics and residence, West Gojam zone, 2012

\begin{tabular}{|c|c|c|c|c|}
\hline $\begin{array}{l}\text { Variable } \\
\text { Age }\end{array}$ & $\begin{array}{c}\text { Urban }(N=104) \\
\text { No }(\%)\end{array}$ & $\begin{array}{c}\text { Rural }(\mathbf{N}=210) \\
\text { No }(\%)\end{array}$ & $\begin{array}{c}\text { Total } \\
\text { No }(\%)\end{array}$ & $\begin{array}{c}\text { P-value } \\
0.14\end{array}$ \\
\hline $18-20$ & $96(92.3)$ & $182(86.7)$ & $278(88.5)$ & \\
\hline $21-24$ & $8(7.7)$ & $28(13.3)$ & $36(11.5)$ & \\
\hline Sex & & & & 0.493 \\
\hline Male & $75(72.8)$ & $145(69.0)$ & $220(70.3)$ & \\
\hline Female & $28(27.2)$ & $65(31.0)$ & $93(29.7)$ & \\
\hline Religion & & & & $0.014 *$ \\
\hline Orthodox Christian & $97(93.3)$ & 206(98.6) & $303(96.8)$ & \\
\hline Muslim & $7(6.7)$ & $2(1.0)$ & $9(2.9)$ & \\
\hline Protestant Christian & $0(0)$ & $1(0.5)$ & $1(0.3)$ & \\
\hline Living arrangement & & & & $<0.001^{*}$ \\
\hline Both biological parents & $54(51.9)$ & $7(3.6)$ & $61(20.4)$ & \\
\hline One biological parent only & $35(33.7)$ & $5(2.6)$ & $40(13.4)$ & \\
\hline Friends & $0(0)$ & $98(50.3)$ & $98(32.8)$ & \\
\hline Alone & $1(1.0)$ & $37(19.0)$ & $38(12.7)$ & \\
\hline Relatives & $14(13.5)$ & $48(24.6)$ & $62(20.7)$ & \\
\hline Attachment to religious institutions & & & & $0.034 *$ \\
\hline Attends frequently & $65(63.7)$ & $152(73.4)$ & $217(70.2)$ & \\
\hline Seldom attends & $35(34.3)$ & $55(26.6)$ & $90(29.1)$ & \\
\hline Not religious & $2(2.0)$ & $0(0)$ & $2(.6)$ & \\
\hline Educational status of mother & & & & $<0.001 *$ \\
\hline Illiterate & $66(64.1)$ & $180(86.5)$ & $246(79.1)$ & \\
\hline Literate & $37(35.9)$ & $28(13.5)$ & $65(20.9)$ & \\
\hline Educational status of father & & & & $<0.001^{*}$ \\
\hline Illiterate & $47(46.1)$ & $138(69.3)$ & $185(61.5)$ & \\
\hline Literate & $55(53.9)$ & $61(30.7)$ & $116(38.5)$ & \\
\hline
\end{tabular}

Table 2. Bivariate and multiple logistic regression analyses for sexual activity according to selected determinants, West Gojam zone, 2012.

\begin{tabular}{|c|c|c|c|c|}
\hline \multirow{2}{*}{ Characteristics } & \multicolumn{2}{|c|}{ Sexual intercourse } & \multirow{2}{*}{ Crude OR[95\%CI] } & \multirow{2}{*}{ Adjusted OR[95\%CI] } \\
\hline & $\operatorname{Yes}(n, \%)$ & $N o(n, \%)$ & & \\
\hline Total & $73(23.2)$ & $241(76.8)$ & & \\
\hline \multicolumn{5}{|l|}{ Residence } \\
\hline Urban & $15(14.4)$ & $89(85.6)$ & 1.00 & \\
\hline Rural & $58(27.6)$ & $152(72.4)$ & $2.2691 .21,4.23)^{*}$ & $2.96(0.83,10.54)$ \\
\hline \multicolumn{5}{|l|}{ Living arrangement } \\
\hline Both biological parents & $7(11.5)$ & $54(88.5)$ & 1.00 & \\
\hline One biological parent & $9(22.5)$ & $31(77.5)$ & $2.24(0.76,6.61)$ & $1.33(0.37,4.79)$ \\
\hline Relatives & $16(25.8)$ & $46(74.2)$ & $2.68(1.02,7.09)^{*}$ & $0.98(0.24,3.99)$ \\
\hline Friends & $28(28.6)$ & $70(74.2)$ & $3.09(1.25,7.60)^{*}$ & $1.04(0.24,4.58)$ \\
\hline Alone & $11(28.9)$ & $27(71.1)$ & $3.14(1.10,9.02)^{*}$ & $0.78(0.15,4.17)$ \\
\hline \multicolumn{5}{|l|}{ Age } \\
\hline $18-20$ & $54(19.4)$ & $224(80.6)$ & 1.00 & \\
\hline $21-24$ & $19(52.8)$ & $17(47.2)$ & $4.64(2.26,9.51)^{*}$ & $3.84(1.40,8.69)^{*}$ \\
\hline \multicolumn{5}{|l|}{ Parental monitoring } \\
\hline Lower & $39(29.3)$ & $94(70.7)$ & $1.97(1.15,3.37)^{*}$ & $1.63(0.83,3.18)$ \\
\hline More & $31(17.4)$ & $147(82.6)$ & 1.00 & \\
\hline \multicolumn{5}{|l|}{ Peer pressure to have sex } \\
\hline Yes & $41(40.6)$ & $60(59.4)$ & $3.97(2.29,6.88)^{*}$ & $3.71(1.84,7.50)^{*}$ \\
\hline No & $31(14.7)$ & $180(85.3)$ & 1.00 & \\
\hline \multicolumn{5}{|l|}{ Best Friend experienced sex } \\
\hline No & $36(20.2)$ & $142(79.8)$ & 1.00 & \\
\hline Yes & $29(47.5)$ & $32(52.5)$ & $3.57(1.92,6.66)^{* *}$ & $3.73(1.57,8.85)^{*}$ \\
\hline Don't Know & $8(10.7)$ & $67(89.3)$ & $0.47(0.21,1.07)$ & $0.40(0.15,1.06)$ \\
\hline \multicolumn{5}{|l|}{ How many of your friends have had sex? } \\
\hline None of them & $18(15.8)$ & $96(84.2)$ & 1.00 & \\
\hline Few of them & $37(28.0)$ & $95(72.0)$ & $2.08(1.1,3.9)^{*}$ & $1.48(0.65,10.81)$ \\
\hline Half of them & $9(23.7)$ & $29(76.3)$ & $1.66(0.67,4.1)$ & $0.68(0.16,2.27)$ \\
\hline Most of them & $9(33.3)$ & $18(66.7)$ & $2.67(1.1,6.9)^{*}$ & $0.33(0.08,1.34)$ \\
\hline Perceived family connectedness score & & & $0.946(0.92,0.98)^{*}$ & $0.95(0.92,0.99)^{*}$ \\
\hline
\end{tabular}




\subsection{Sexual Behaviour}

Interviewees were asked if they had ever had sexual intercourse with an individual of the opposite sex, and 73 $(23.2 \%)$ said they had. Disaggregated by sex, $55(25.0 \%)$ of males had had sex compared to $18(19.4 \%)$ of females. Amongst the schools, the percentage of students that had ever had sex was highest in the Kuarit (42.1\%) and lowest in Merawy (3.3\%) preparatory school.

Thirty six $(53.7 \%)$ of sexually experienced students reported that their first sexual partner was a boy/girl friend, $15(22.4 \%)$ a family member, $13(19.4 \%)$ a stranger, and 3 $(4.5 \%)$ a teacher. More boys (25.0\%) than girls $(19.4 \%)$ and more rural $(27.6 \%)$ than urban students $(14.4 \%)$ reported having had sex [OR $=1.38,95 \% \mathrm{CI} 0.76$ to 2.53 , and $\mathrm{OR}=$ $2.26,95 \%$ CI 1.12 to 4.23 , respectively]. The proportion of sexually active adolescents rose from $19.4 \%(54 / 278)$ among the age group $18-20$ to $52.8 \%(19 / 36)$ in the age group $21-24$ years [OR $=4.64 ; 95 \% \mathrm{CI} 2.26$ to 9.51 ]

Most students $(69.1 \%)$ reported attending religious institutions frequently; however, the proportion of students reporting sexual activity didn't differ significantly with respect to religious attachment.

Students who lived with their relatives, with friends, or alone were significantly more likely to report sexual activity than those who lived with both biological parents [OR=2.68; $95 \% \mathrm{CI} 1.02$ to $7.09, \mathrm{OR}=3.09 ; 95 \% \mathrm{CI} 1.25$ to 7.60 and $\mathrm{OR}=3.14 ; 95 \% \mathrm{CI} 1.10$ to 9.02 respectively].

Of the sexually active students, $50(71.4 \%)$ reported contraceptive use at first intercourse. Overall, 72.1\% (49/68) students reported contraceptive use at their most recent sexual intercourse and of these, $37 \%$ (17/46) used a condom.

Consistent condom use was reported by $6(12.2 \%)$ males and no female and did not differ significantly by gender. Among the sexually active males, $3(6.3 \%)$ reported having had sexual intercourse with commercial sex workers of which only one had used a condom consistently.

\subsubsection{Communication and Discussion Regarding Sexuality and HIV/AIDS}

Overall, 283 (90.1\%) students reported that they had ever discussed sexuality or HIV/AIDS, mostly (65.1\%) with their same sex peers. Compared to urban students, rural ones were significantly more likely to discuss with teachers ( $\mathrm{p}$-value $<0.05$ ). More males than females reported discussion with friends of the same sex $[\mathrm{OR}=1.76,95 \% \mathrm{CI}$ 1.04 to 2.98$]$.

Health practitioners and mass media were the dominant sources of information regarding sexuality and HIV/AIDS, mentioned by $196(68.8 \%)$ and $169(59.3 \%)$ of students respectively. There was no significant gender difference with regard to the dominant source of information regarding sexuality and HIV/AIDS. A significantly higher proportion of rural students mentioned health practitioners $(70.8 \%$ versus $47.1 \%$; $p$ - value $<0.001$ ), as the most important source of information.

\subsubsection{Peer Influence and Behaviour}

One hundred one (32.2\%) respondents indicated that they were under pressure from friends to engage in pre-marital sex, and $19.9 \%$ indicated that the pressure was moderate or high. There was no significant difference by residence or gender in reported peer pressure and behaviour. Students who had peer pressure to have sexual intercourse and those who had friends already engaging in sexual intercourse were more likely to have sexual experience. $(\mathrm{p}=0.004$ and $\mathrm{p}<.001$ respectively)

One hundred four (47.9\%) boys claimed that few of their peers have started sexual intercourse, while $23(10.6 \%)$ claimed that most of their peers had started sexual intercourse; boys being more likely to report that most of their peers had started sex (p-value $<0.001)$.

Regarding peer behaviour, 28 (30.1\%) female students reported that few of their peers had started sexual intercourse, while $4(8.6 \%)$ believed that most of their peers had started sexual intercourse. Rural girls were significantly more likely to report that few/most of their peers had started sex $(\mathrm{p}$-value $=0.002)$.

\subsubsection{Perceived Family Connectedness}

Parent-teen connectedness was measured using a 10-item scale ((Cronbach's $\alpha=0.954$ overall, 0.947 for mother score and 0.964 for father score) based on adolescent report. Questions ask teens how close they feel to their mothers/father, how much they believe their mothers/fathers care about them, how warm and loving they perceive their mothers/fathers to be, and how satisfied they are with their relationship with their mothers/fathers. Students who answered 'don't know' or 'not applicable' were assigned the student's mean score for the set excluded from the analyses for family connectedness. Family connectedness scores were analyzed as a continuous variable with possible values ranging from 10 to 50 .

The perceived family connectedness scale ranged from 10 to 50 . Nine (3.4\%) scored 20 or lower, $54(20.4 \%)$ scored $21-40$ and $202(76.2 \%)$ scored 41-50. Sexually active students had a significantly lower level of perceived family connectedness. There was no statistically significant difference in mean family connectedness score by gender, residence (urban versus rural) or living arrangement

\subsubsection{Perceived Parental Monitoring}

Parental monitoring was assessed using 2 questions that asked adolescents whether their parents knew where they were and who they were with when not at school and away from home. The scale had a reliability coefficient (Cronbach's $\alpha$ ) of 0.70 . Adolescents were categorized into 2 groups: those responding most of the times (4) and almost always (5) to each of the items, were classified as exposed to more parental monitoring; the rest were categorized as having less parental monitoring.

Of the 314 students participating in the study, 133 (42.8\%) were categorized as having less perceived parental 
monitoring. In the bivariate analysis, less perceived parental monitoring was associated with male sex, being a rural student, living alone or with friends, and sexual activity.

\section{Discussion}

Nearly a quarter of preparatory school students in west Gojam zone have had sexual intercourse. This demonstrates that many adolescents are confronted at some point during their teen years with choices about whether or not to have sex and, if they do, whether or not to use condoms and/or other contraceptives. Many factors affect those choices. This sexual initiation prevalence is higher than that found from the BSS 2005 [7], which revealed 9.9\% of in school adolescents were sexually active and lower than others[8,9] which were around $33 \%$ but almost consistent with a study by Dessalegn which was $21.4 \%$ [9]. This discrepancy may be due to that there is a difference among study participants of the different studies.

The majority $(59.7 \%)$ of sexually active in school adolescents engaged in premarital sexual relationship before celebrating their 18th birthday. Many studies also indicated that secondary school students are becoming sexually active at an increasing earlier age [9-11]. This early initiation of sexual activity prolongs the period of exposure to risk of pregnancy and risk of contacting STDs, including HIV infection during the reproductive span. Mean age of sexual initiation was not found significantly associated with sex or residence. But when we see the mean age of students' sexual partners age at sexual debut, female students were more likely to have older partner who are more likely to have HIV infection, consistent with previous study done in Dessie[5].

Generally students' knowledge about sexual and reproductive health issues is unsatisfactory regardless of their sex or residence and was not found to be associated with sexual activity. This may indicate that, even though knowledge is important predisposing factor to adopt healthy sexual behaviour, focusing only on acquisition of knowledge will not bring about the intended out comes. Adolescent related intervention on health information dissemination should be tailored or targeted.

As is commonly recognized, youth are influenced by their peers and peers influence teens' sexual behavior. Peer pressure and sexual behaviour is another environmental variable that believed to have effect on adolescents' sexual activity. This particular study proved that students claimed having had peer pressure to engage in premarital sex were more likely to report sexual activity. This is consistent with some previous studies [5]. There was no statistically significant difference peer pressure in relation to sex or residency.

Findings related to parent-teen connectedness did not differ related to residence, living arrangement or sex. Generally high levels of parent-teen connectedness were independently related to delays in sexual debut. Parent-teen connectedness has emerged in recent research as a compelling "super- protector"- a feature of family life that may buffer young people from the many challenges and risks facing them in today's world. There is a marked consistency in this body of about two dozen studies; all but a few indicate that parent-child closeness acts as a protective factor for the prevention of a variety of health and social problems (whether the outcome of interest is overall adjustment and functioning, substance use, sexual behavior, STI/HIV, suicide, conduct disorder or violence). Parent-teen connectedness is associated with reduced adolescent pregnancy risk through teens remaining sexually abstinent, postponing intercourse, having fewer sexual partners, or using contraception more consistently.[12-17]

Social science research has demonstrated that parental involvement affects adolescent behavior, primarily through monitoring behavior on the part of parents. Parents who spend more time supervising their children have children who engage in fewer risky behaviors. We have also tried to see the relationship between perceived parental monitoring and sexual behaviors of the students, but unlike to many other studies [5, 13-17] we did not get significant association. This inconsistency may be due to the fact that the type of monitoring differs across different settings needed to be addressed in detail in this particular study area. If the monitoring is coercive types it may not bring abut positive behavioural changes, even sometimes results in negative outcomes.

Significant number $(90.1 \%)$ of students reported that they had ever discussed sexuality or HIV/AIDS. We have tried to investigate parent-teen communication as another dimension in family relationship and found not to be significantly associated with sexual activity. This is also consistent with previous studies $[13,16]$ and unlike to other studies which showed significant association with sexual activity[18]. Here, the relationship may vary by the content and degree of discussion as well as other factors.

In the multivariate logistic regression analyses, age of more than 20 years, having peer pressure to have sex and lower perceived family connectedness continued to be associated with sexual activity.

\section{Conclusion}

This particular study indicates that a substantial proportion of adolescents in preparatory school in general and those who came from the surrounding in particular are sexually active.

Perceived parent-teen relationships characterized by high levels of warmth and closeness, is important protective factors related to delay in adolescents' first sexual intercourse

Students experiencing peer pressure to have sex are more likely to engage in premarital sexual activities.

The level of sexual and reproductive health knowledge that students have is generally unsatisfactory and has not been associated with being sexually abstinent and condom use. 
Communication on sexual issues is not associated with safe sexual behavior. Mass media was the dominant source of information regarding issues related to sexuality and HIV/AIDS.

Most adolescents rely on health practitioners and teachers to get information and guidance on issues related to sexuality and HIV/AIDS.

Students who had high perceived family connectedness were less likely to report history of Khat consumption

Sexual activity among rural students is particularly high and most of them use condoms inconsistently despite better reproductive health knowledge.

The most commonly used contraceptive used both at sexual debut and last intercourse is the condom but consistent use is generally low.

\section{References}

[1] Hibist, A. and S. Robert, Testing the Application of a Western Scientific Theory of AIDS Risk Behavior Among Adolescents in Ethiopia. Journal of Pediatric Psychology, 2000. 25(6): p. 367-379

[2] International Planned Parenthood Federation. Understanding Adolescents, in An IPPF Report on Young People's Sexual and Reproductive Health Needs,Lodon. 1994.

[3] O.Bayley, Improvement of sexual and reproductive health requires focusing on adolescents. . Lancet, 2003. 362: p. $832-41$.

[4] Runganga, A.O. and P. Aggleton, Migration, the family and the transformation of a sexual culture Sexualities, 1998. 1(1): p. $63-81$.

[5] Solomon, S., The Effect of Living Arrangements and Parental Attachment on Sexual Risk behaviors and Psychosocial Problems of Adolescents in Dessie Preparatory School, Ethiopia. 2004.

[6] Resnick MD, et al., Protecting adolescents from harm: findings from the national longitudinal study on adolescent health. . JAMA, 1997. 278: p. 823-832.
[7] Getnet, M., et al., HIV/AIDS Behavioral Surveillance Survey (BSS) Ethiopia 2005. 2005.

[8] Adamu R, Mulatu MS, and H. SI., Patterns and correlates of sexual initiation, sexual risk behaviors, and condom use among secondary school students in Ethiopia. Etiopian medical Journal 2003. 41(2): p. 163-77.

[9] Dessalegn, W., An assessment of premarital ssexual practice and factors contributing to premarital sex among high school adolescents in Nekemte town,East Wolleg zone,Oromia Regional State. 2006.

[10] Astatke, H., M. Black, and R. Serpell, Use of Jessor's theoretical framework of adolescent risk behavior in Ethiopia: implications for HIV / AIDS prevention. Northeast African Studies, 2000. 7(1): p. 63-83.

[11] Helmut, K., H.M. Damen, and L. Bernt, The AIDS Epidemic in a Low-Income Country: Ethiopia. Human Ecology Review, 2007. 14(1): p. 39-35.

[12] Springer, A., et al., Perceived parental monitoring and health risk behavior among public secondary school students in El Salvador. ScientificWorldJournal., 2006. 28(6): p. 1810-4.

[13] Brener, N., et al., Trends in Sexual Risk Behaviors Among High School Students --- United States, 1991--2001. MMWR(CDC), 2002. 51(38): p. 856-859

[14] Borawski, E., et al., Parental monitoring, negotiated unsupervised time, and parental trust: the role of perceived parenting practices in adolescent health risk behaviors. Journal of Adolesc Health., 2003. 33(2): p. 60-70.

[15] Li, X., B. Stanton, and S. Feigelman, Perceived parental monitoring and health risk behaviors among urban low-income African-American children and adolescents. Journal of Adolesc Health, 2000. 27(1): p. 43-8.

[16] family.jrank.org, Sexuality in Adolescence - Correlates And Outcomes, M.a.F. Encyclopedia, Editor. p. 1523.

[17] Li, X., B. Stanton, and S. Feigelman, Impact of perceived parental monitoring on adolescent risk behavior over 4 years. Journal of Adolesc Health., 2000. 27(1): p. 49-56.

[18] Karofsky, Zeng, and Kosorok, Relationship Between Adolescent-Parental Communication and Initiation of First Intercourse by Adolescent. 